\title{
A EXTENSÃO NOS CURSOS DE DESIGN DE PRODUTO: INTERAÇÃO ENTRE A UNIVERSIDADE E A COMUNIDADE, INTERNA E EXTERNA, UTILIZANDO A MODELAGEM 3D COM PROCESSOS ANALÓGICOS E DIGITAIS
}

Eliete Auxiliadora Assunção Ourives, Dra Universidade Federal de Santa Catarina elieteourives@gmail.com

Alais Souza Ferreira

Especialização em Marketing Criativo UNIVALI

alais.ferreira@live.com

Luiz Fernando Gonçalves de Figueiredo, Dr. Universidade Federal de Santa Catarina Iffigueiredo2009@gmail.com
Milton Luiz Horn Vieira, Dr. Universidade Federal de Santa Catarina milton@cce.ufsc.br

Ludmilla Gonçalves de Figueiredo Graduada em Serviço Social - UFSC ludy.figueiredo@gmail.com

Vinícius Dallagnol Mestrando em Design - UFSC vinikamikase@gmail.com

Resumo: O projeto de extensão através de parceria e cooperação na área da educação e tecnologia, visando à interação entre a comunidade interna, proporciona conhecimento para alunos, professores e profissionais na área de Design de Produto. O projeto gráfico para o Design de produto utiliza como prática a modelagem de maquetes 3D reais e digitais, é uma atividade importante por proporcionar a ligação e integração entre a Escola de Ensino Médio e o Curso Superior, apresentando vantagens para as duas instituições de ensino. Dessa forma, esta proposta de projeto de extensão tem como objetivo geral integrar a comunidade interna e externa através do ensino da modelagem 3D digital e analógica. O método de pesquisa deste artigo tem caráter descritivo e exploratório, classificando-se como um projeto de extensão na área de Design de Produto que apresenta protótipos com etapas de práticas diferenciadas para a integração da Universidade e Ensino médio. Ao final, este trabalho vem contribuir apresentando propostas com trocas de conhecimento e responsabilidade conjunta, etapas com dados que mostram as necessidades da comunidade, aspirações para melhor interatividade profissional, características e a cultura da população abordada.

Palavras-chave: modelagem 3D, projeto de extensão, protótipos.

Abstract: The project of extension through partnership and cooperation in the area of education and technology, aiming at the interaction between the internal community, provides knowledge to students, teachers and professionals in the field of Product Design. The graphic design for the Product Design uses as practice the modeling of maquettes real and digital $3 D$, is an important activity for providing the connection and integration 
between high school and higher education, showing advantages for the two institutions of teaching. Thus, this proposed extension project aims to integrate internal and external community through teaching of analog and digital 3D modeling. The method of research of this article has descriptive and exploratory character, classifying it as an extension project in the area of Product Design that presents prototypes with practical steps differentiated for integration of University and high school. In the end, this work comes to contribute presenting proposals with exchanges of knowledge and joint responsibility, steps with data that show the community's needs, aspirations for better interactivity professional, features and culture of the population addressed.

keywords: 3D modeling, extension project, prototypes.

\section{INTRODUÇÃO}

A universidade pública se torna plena ao proporcionar formação técnica de profissionais e atuar junto à comunidade como agente de transformação sociocultural, gerando visibilidade social para as suas três missões: ensino, pesquisa e extensão. Os projetos de extensão podem incluir interação com atividades que envolvem: pesquisa aplicada; difusão de conhecimentos; ensino a distância e busca de parcerias de cooperação nas áreas da saúde, meio ambiente, trabalho, emprego, cultura, esporte, educação, tecnologia industrial, etc. (THIOLLENT et al, 2000).

Este projeto de extensão visa buscar parceria de cooperação na área da educação e tecnologia, através de atividades de interação entre a comunidade interna (universidade, professores, profissionais da área, técnicos da universidade, alunos de graduação em Design de Produto, de mestrado e doutorado de Programas de PósGraduação em Design e áreas afins) e externa (ensino médio, público e particular; ensino profissionalizante e empresas), que irão participar sendo efetivos e proporcionar conhecimento para alunos, professores e profissionais da área.

Como atividade de interação, será realizada a integração entre uma Escola de Ensino Médio e o Curso Superior de Design de Produto, tendo como "elo" de ligação o projeto gráfico que utiliza como prática a modelagem de maquetes 3D reais e digitais. Será descrito o modo de trabalho dessa atividade, como se desenvolve as interações com a escola e as vantagens para as duas instituições de ensino, destacando a seleção e a adequação das atividades práticas sugeridas para a formação profissional.

Essas atividades devem incentivar a liderança, o trabalho em equipe, a administração de desafios, a busca de resultados para a equipe de alunos designada para o trabalho com a escola, e motivar os alunos de ensino médio a ingressar no curso de Design de Produto na UFSC. Também trarão oportunidades para que alunos da graduação e pós-graduação exponham seus trabalhos de pesquisa com linguagem adequada para o ensino médio, constituindo em uma contribuição importante para a formação dos alunos de design de produto, despertando-os para a docência.

Além disso, as atividades visam divulgar os conhecimentos de Design de Produto/Expressão Gráfica/Desenho Técnico e suas especificidades no curso superior, articulando conteúdo e didática para o desenvolvimento do Projeto de Extensão. 
Acredita-se que essa forma de divulgação (com palestras de professores universitários em escolas, mostras de vídeos, etc) desse curso possam despertar nos jovens do ensino médio o interesse pelo conhecimento nessa área, como também fomentar escolhas de futuras profissões relacionadas a ela contribuindo na formação científicocultural desses jovens participantes.

Nessa concepção, o aluno é o centro da aprendizagem e os professores devem ser um agente facilitador, propiciando as informações e os procedimentos necessários para despertar a motivação dos alunos. Esse método modifica o ambiente de aprendizado, trazendo o aluno da sala de aula convencional para um ambiente de pesquisa gerador de novos conhecimentos, onde o aluno poderá: observar, ouvir, sentir e se expressar frente à nova experiência.

Quanto à formação cultural, os alunos podem fazer contatos e compreenderem a influência de aspectos importantes da tecnologia que repercutem nos modos de vida da sociedade, fazendo com que as interações entre seus membros sejam influenciadas por esses meios. Nesse sentido, os estudantes do ensino médio poderão aumentar sua percepção das relações entre a modelagem real e digital 3D, os cursos de Design de Produto, e a importância do seu aproveitamento na sociedade. Além da possibilidade de conhecer equipamentos e materiais diferenciados na construção da maquete real, também são apresentados os programas de computador parametrizados e não parametrizados para a elaboração da maquete digital, e qual a diferença e importância no curso de design de produto.

De acordo com Bastos e colaboradores (2005) a Educação, no escopo da Ciência e Tecnologia, tem lugar de destaque nas transformações da sociedade e na formação do sujeito que atua nela. Segundo os autores, a adesão a essas tecnologias não deve acontecer de forma incondicional como se fossem solucionar todos os problemas da educação, necessita explorar as potencialidades desses recursos nas situações de ensino-aprendizagem e evitar o uso indiscriminado da tecnologia apenas por suas virtualidades técnicas sem lembrar as virtudes pedagógicas. Neste projeto de extensão, deve-se lembrar de que o esboço, os croquis, os desenhos e as maquetes físicas continuam sendo instrumentos que contribuem significantemente no processo de ensino. Por isso, integrar o sistema analógico ao digital através da modelagem 3D favorece e fortalece o processo de ensino-aprendizagem na área de expressão gráfica, projetos gráficos, desenho técnico no curso de design de produto.

\section{A modelagem real e digital 3D no ensino}

O termo modelar, segundo o dicionário da Língua Portuguesa, designa a representação de alguma coisa, é aquilo que serve de referência ou é dado para ser produzido. Segundo Scheffer (1999) representa uma situação real e pode ser uma figura, desenho, maquete, fórmula. Para Biembengut e Hein (2000) o modelo retrata, em uma visão simplificada, aspectos da situação pesquisada. O modelo é, então, uma imagem que se forma quando o indivíduo tenta compreender e expressar alguma sensação, relacionando-a com algo que já conhece (SCHEFFER \& DALLAZEN, 2008).

Para Speck (2005), modelar é representar ideias abstratas, trabalhos e formas, através do uso ordenado de texto simplificado e imagens com a finalidade de pensar, visualizar, comunicar, predizer, controlar e treinar. Modelos descritivos representam ideias abstratas, produtos ou processo, como uma maquete eletrônica ou modelagem 
3D de uma peça mecânica. E modelos preditivos são usados para entender e predizer o comportamento/performance de ideias, produtos ou processo.

“As representações gráficas em 3D têm assumido papel [...] destacado nas áreas de projeto e design, em face da maior facilidade que os software gráficos atuais apresentam no seu desenvolvimento e também por sua variada aplicabilidade" (SPECK, 2005, p.34). O autor informa que a vantagem da modelagem 3D (tridimensional) é a possibilidade do usuário trabalhar com o objeto na sua forma real sem a preocupação de interpretá-la, mas pode apresentar erros de interpretação quando as peças são complexas, com muitos detalhes. Essa modelagem pode ser aplicada no Design de Produto, entre outros cursos, o quadro 1 apresenta exemplo de algumas aplicações.

\section{Quadro 1 - Áreas de aplicação de modelagem 3D}

\begin{tabular}{|l|l|}
\hline Área & Aplicação \\
\hline Automação & $\begin{array}{l}\text { Modelos 3D utilizados para fabricação de protótipos por máquinas monitoradas } \\
\text { por computador e que suportam ferramentas CAD/CAM, permitindo a } \\
\text { integração direta entre projeto e produto. }\end{array}$ \\
\hline Simulação & $\begin{array}{l}\text { Modelos 3D utilizados para testes mecânicos diversos, sob diferentes condições, } \\
\text { para verificação das características mecânicas e de resistência de peças. }\end{array}$ \\
\hline $\begin{array}{l}\text { Projeto } \\
\text { arquitetônico }\end{array}$ & $\begin{array}{l}\text { Maquetes eletrônicas utilizadas como ferramenta básica no desenvolvimento de } \\
\text { realidade virtual, permitindo ao cliente "andar" interna e externamente pela } \\
\text { futura residência ou "passear" pela planta da futura indústria. }\end{array}$ \\
\hline $\begin{array}{l}\text { Conjuntos } \\
\text { arquitetônicos, } \\
\text { históricos }\end{array}$ & $\begin{array}{l}\text { Projetos de reconstrução e restaurações, as maquetes têm servido como } \\
\text { ferramenta fundamental no estudo de desenvolvimento e viabilidade de } \\
\text { recuperação dessas construções. }\end{array}$ \\
\hline Desenho técnico & $\begin{array}{l}\text { Facilita a obtenção de vistas ortográficas, auxiliares primárias e secundárias a } \\
\text { partir dos modelos 3D, através de interações de interfaces que facilitam e } \\
\text { sistematizam o trabalho do projetista. }\end{array}$ \\
\hline Inspeção & Inspeção de produtos após prototipagem. \\
\hline
\end{tabular}

Fonte: Adaptado de Speck (2005, p.34-35).

Em relação à modelagem parametrizada, Speck (2005) afirma que o projeto paramétrico permite gerar muitas informações sobre o desenho, e para obter estas informações é necessário primeiro modelar suas partes ou peças componentes. Os modelos parametrizados são esculpidos na forma de volumes sólidos de materiais.

O projeto global é dividido em componentes básicos, através de blocos ou peças básicas que são modelados usando os comandos de extrusão, revolução, sweep (varredura) e blend (fundir). Características adicionais podem ser esboçadas (pescoço, rosca, flange e corte) e características como escolher e deslocar as partes para a sua respectiva posição, chamando os perfis de referência, completa o projeto (furos, círculos e chanfros). Existem três métodos distintos para modelagem geométrica, wireframe (armação em arame), superfície e modelos sólidos. (SPECK, 2005).

$\mathrm{O}$ quadro 2 descreve três métodos de modelagem geométrica, suas vantagens e desvantagens. 
Quadro 2 - Vantagens e desvantagens dos métodos de modelagem geométrica.

\begin{tabular}{|c|c|}
\hline Método 1 & Wireframe \\
\hline Descrição & $\begin{array}{l}\text { Não há superfícies, apenas vértices, linhas retas e curvas que representam as } \\
\text { arestas de um objeto 3D. É a descrição do "esqueleto" ou da "estrutura" de um } \\
\text { objeto tridimensional. }\end{array}$ \\
\hline Vantagem & $\begin{array}{l}\text { É utilizado em aplicações que necessitam da visualização das arestas de } \\
\text { objetos 3D, possibilitando facilidades com respeito ao desenho em 3D. }\end{array}$ \\
\hline Desvantagem & Nível pequeno de descrição dos sólidos que representam. \\
\hline Exemplo/Aplicação & $\begin{array}{l}\text { Aplicações esquemáticas, onde o modelo é substituído por linhas, que } \\
\text { representam o contorno, linhas de fluxo, cabos ou tubulações. }\end{array}$ \\
\hline Método 2 & Superfície \\
\hline Descrição & $\begin{array}{l}\text { Contém informações sobre as arestas de um objeto e o espaço entre elas. } \\
\text { Pode ser idealizado como uma "casca" de um objeto 3D, identificando pontos } \\
\text { que podem estar "dentro" ou "fora". }\end{array}$ \\
\hline Vantagem & $\begin{array}{l}\text { Detêm um nível maior de descrição dos objetos, sendo utilizado em aplicações } \\
\text { que necessitam de mais informações. }\end{array}$ \\
\hline Desvantagem & $\begin{array}{l}\text { Os dados necessários para análise por elementos finitos, análises volumétricas } \\
\text { e da massa e para cálculos de momentos de inércia, podem ser melhor obtidos } \\
\text { por meio de modelagem de sólidos. }\end{array}$ \\
\hline Exemplo/Aplicação & $\begin{array}{l}\text { Superfícies de terrenos (curvas de nível para levantamento topográfico), ou } \\
\text { complexas pertencentes à peças utilizadas nas indústrias automobilística, } \\
\text { aeroespacial, entre outras. }\end{array}$ \\
\hline Método 3 & Modelos sólidos \\
\hline Descrição & Cria objetos tridimensionais a partir de sólidos (cubos, esferas ou cones). \\
\hline Vantagem & $\begin{array}{l}\text { É uma forma de modelagem mais realista, muda sua geometria, por operações } \\
\text { booleanas e efetua análises, associando as propriedades físicas e materiais ao } \\
\text { objeto. }\end{array}$ \\
\hline Desvantagem & $\begin{array}{l}\text { O modelamento 3D apresenta as dificuldades que são próprias do processo de } \\
\text { desenho, pois o projetista é obrigado a considerar as três dimensões } \\
\text { simultaneamente. }\end{array}$ \\
\hline Exemplo/Aplicação & $\begin{array}{l}\text { Redução do ciclo de desenvolvimento dos produtos, desde sua concepção até } \\
\text { a sua produção para o mercado. Personalização de produtos, fabricação de } \\
\text { protótipos, produtos em pequenas séries. }\end{array}$ \\
\hline
\end{tabular}

Fonte: Adaptado de Speck (2005).

Bandeira e colaboradores (2008), no trabalho desenvolvido pressupõem o encontro da arte e tecnologia a partir da expressão artística aliada às novas tecnologias, por meio de novas mídias e ferramentas para produção gráfica. Eles definem elementos estilísticos e conceituais dos cenários de um RPG educativo através de uma pesquisa histórica, destacando as etapas de produção e criação, vide figura 1. Os autores analisam aspectos de criação de cenários, elaboração de esboços para obtenção de cenas e modelagem 3D, e apresentam aspectos que interferem na concepção e criação de cenários de acordo com os critérios da concept art.

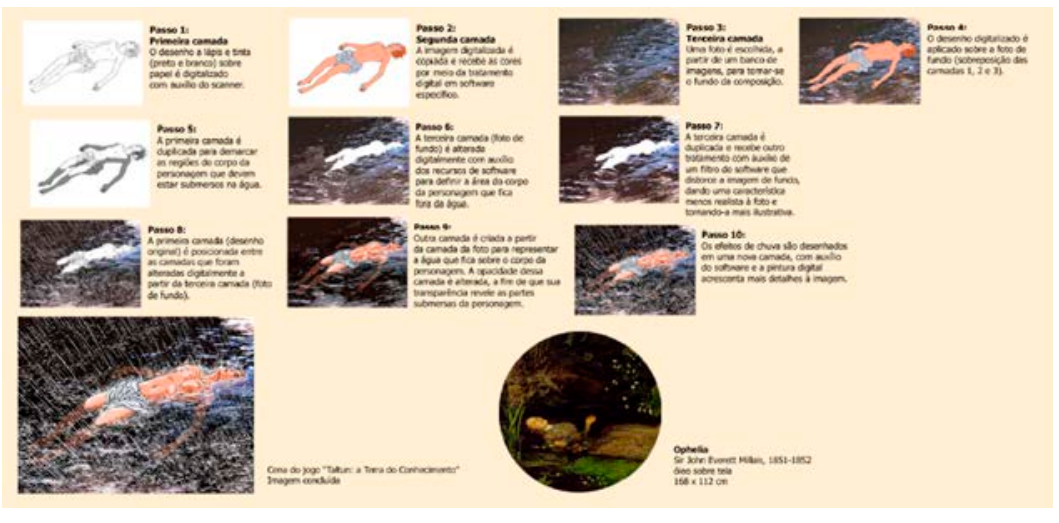

Figura 1 - Etapas do processo de criação de um cenário de jogo "Taltun: a terra do conhecimento". Fonte: Bandeira e colaboradores (2008). 
Santos e colaboradores (2008), verificando que os conteúdos da disciplina referente à Geometria Cotada e Superfícies Topográficas não eram suficientemente desenvolvidos, embora atendessem aos requisitos de motivação, constataram que faziam uso limitado da ferramenta CAD-3D (MicroStation Modeler) e a representação bidimensional não era praticada pelos alunos no desenvolvimento do projeto. Por isso, os autores modificaram o projeto didático contemplando as etapas que não eram praticadas pelos alunos em 3D, conforme demonstra a figura 2.

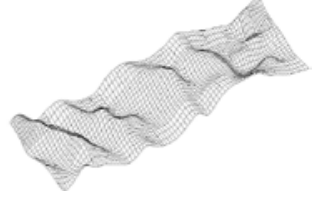

Figura 2 - Superfície 3D do terreno.

Fonte: Santos e colaboradores (2008).

\section{Projeto de extensão no curso de design de produto}

A pesquisa objetiva integrar a comunidade interna e externa através do ensino da modelagem digital e analógica 3D, como atividade de extensão no curso de design de produto. Para alcançar esse objetivo é necessário: trazer o aluno não universitário ao meio acadêmico disponibilizando um ambiente novo e estimulante; despertar a curiosidade, motivação, aprendizado e desenvolver o senso cognitivo dos alunos envolvidos através das atividades propostas; conhecer as tecnologias, equipamentos e materiais diferenciados ou já conhecidos, aplicados ou fabricados de maneiras distintas; oferecer recursos que o professor pode ter como meios para o ensino; divulgar o design de produto como um curso consolidado e de futuro.

Segundo Lakatos \& Marconi (2011), a metodologia de desenvolvimento pode ser classificada como pesquisa aplicada e exploratória, que utiliza técnica da observação, pois seu resultado será imediatamente aplicado na melhoria da qualidade do ensino da representação gráfica nos cursos de design de produto.

A modelagem física e virtual, conduzida como teoria de projeto e atividade de laboratório experimental permite ao aluno lidar com problemas de visualização, dimensionamento, especificação e montagem de subsistemas. $O$ espaço virtual oferece vantagens como modelagem em escala real, flexibilidade na alteração de geometrias, processos seletivos de visualização e diversidade nas formas de apresentação. Explorar estes aspectos desenvolve a cognição e habilidades técnicas, que podem ser aprimoradas quando o aluno emprega na modelagem os produtos relacionados à habilitação que cursa. A modelagem permite ao aluno experimentar uma atividade de integração entre as técnicas gráficas informatizadas e as metodologias de projeto usuais em sua habilitação.

Neste projeto serão apresentados exemplos práticos de conteúdos para o Curso de Design de produto, mas é um método que poderá ser empregado em outras especificidades do design. Ele contempla três etapas descritas a seguir: a apresentação, a prática e o fechamento.

\subsection{Etapa 1 - Apresentação}

A equipe do projeto irá contatar 10 escolas do ensino médio, particulares e públicas da cidade de Florianópolis - SC, para selecionar 4 alunos e 1 professor de qualquer área, que serão inscritos oficialmente no projeto e convidados para conhecer 
a universidade, o departamento e o curso de design de produto. É o momento que será proferido palestras (por designers, ex-alunos, atuantes em empresas de destaque) que abordarão a profissão do designer, suas especificidades de atuação, o curso de graduação e sua história, com o intuito de transmitir a sua importância frente à pesquisa tecnológica e a formação de profissionais na área. Além disso, procura-se informar que o curso de design de produto tem tradição e o profissional tem sido cada vez mais requisitado no mercado de trabalho.

Também é uma oportunidade para os alunos visitarem os diversos setores e laboratórios de Design, conhecendo equipamentos, sistemas de custos e complexidades variadas, além de mostrar o investimento que é realizado em inovação e tecnologia para pesquisa. Nesse momento, os alunos poderão vivenciar o ambiente do laboratório de modelagem física e virtual, os softwares que são utilizados e demonstrações do seu uso, exposição de maquetes físicas, etc, que os ajudarão a ver a pesquisa como uma atividade construtiva e de extrema importância. Também é a ocasião de proferir seminários relacionados aos temas do projeto, por exemplo, para o curso de design de produto mostrando o desenvolvimento de vant, sua utilização e importância no monitoramento ambiental.

\subsection{Etapa 2 - Prática}

Nesta fase o professor orientador e os alunos bolsistas da universidade já estão preparados para receber os alunos e professores do ensino médio para o desenvolvimento da prática na área específica de seus cursos, planos de atividades individuais, cartilhas ou manuais, etc. Durante os encontros serão realizadas palestras proferidas por profissionais designers e professores da área, visitas técnicas. Abaixo é indicada orientações de materiais para a construção física e virtual do personagem.

- Orientação da pesquisa de materiais para a construção física: A finalidade é buscar a formação para as habilidades manuais e espaciais. A pesquisa de materiais pode ser orientada através do diagrama de blocos, para o modelo funcional físico ou/e superfície. A figura 3 mostra o processo de decisão na definição do material para a construção física de um personagem ou outros produtos, neste caso definiu-se a utilização do papel triplex por ser de fácil manuseio, ter superfície lisa e baixo custo. Para a superfície definiu-se o uso de adesivo. Essa é uma forma de apresentar aos alunos os materiais, qual o mais apropriado para aquela função, etc.

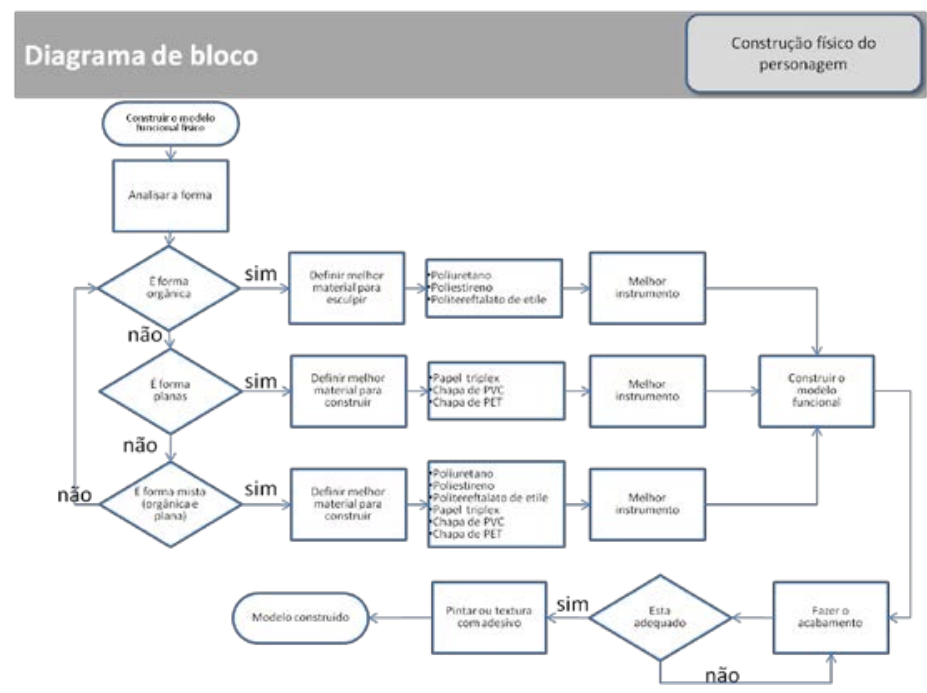

Figura 3 - O diagrama de bloco da construção física do personagem. Fonte: Elaborado pelos autores. 
- Orientação de passos para a construção virtual: A construção do modelo virtual também pode ser orientada pelo diagrama de blocos. A figura 4 apresenta 0 processo de decisão para a construção virtual de um personagem através de qualquer software, esse esquema pode ser utilizado para a construção de outros modelos virtuais. Poderá ser realizada a análise da forma, se o processo for através das vistas ortográficas, etc.

-

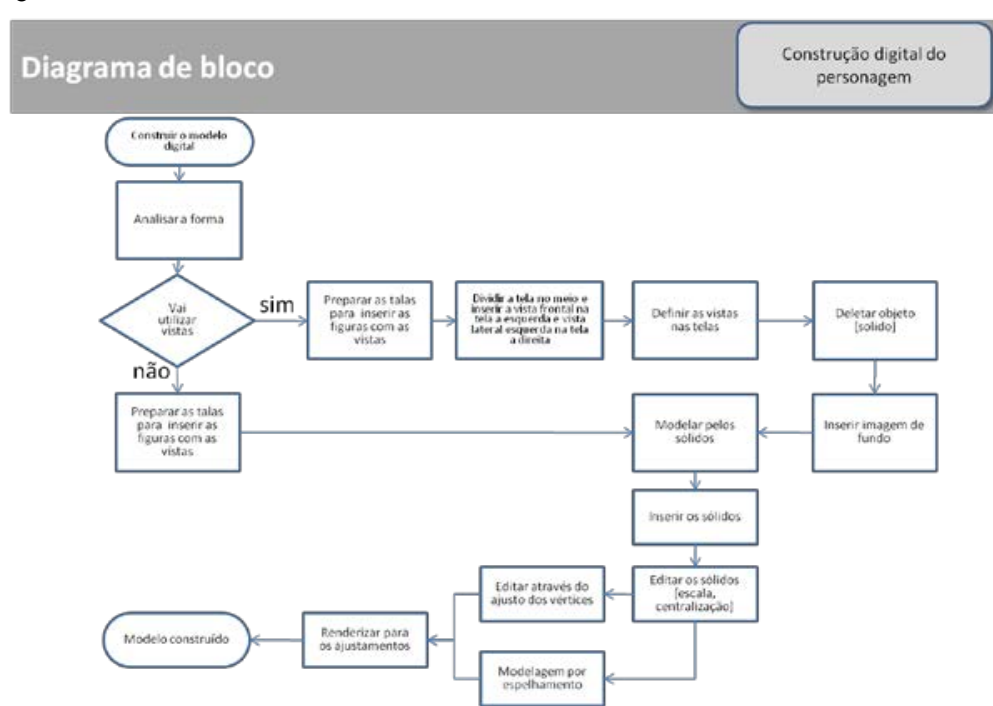

Figura 4 - 0 diagrama de bloco da construção virtual do personagem.

Fonte: Elaborado pelos autores.

A seguir, serão apresentados exemplos de prática, direcionadas aos cursos de Design de Produto, que poderão ser realizadas com os alunos. Porém, podem ser realizadas em outras áreas de design e cursos com práticas semelhantes.

\subsubsection{Prática 1: Uso de vant do bem como tecnologia ambiental inovadora}

Esta prática pode ser desenvolvida no projeto entre a UFSC e a FATMA, em que um dos autores faz parte, e que esta pesquisando veículos aéreos não tripulados para monitoramento ambiental em áreas de Santa Catarina.

- Modelagem física de vant: Serão desenvolvidos veículos aéreos não tripulados nas classes avião, asas e multimotores. Os alunos utilizarão os laboratórios de modelagem para realizarem o projeto, conforme figura 5.

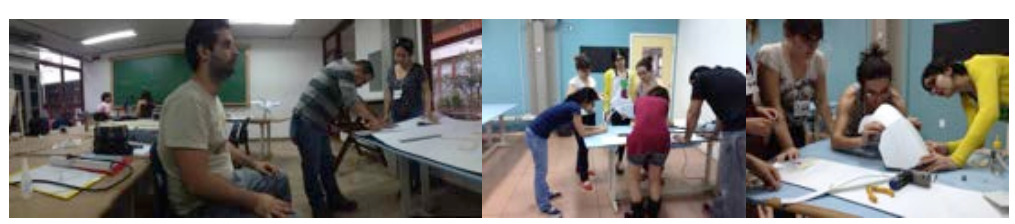

Figura 5 - Exemplo de alunos em atividades.

Fonte: Elaborado pelos autores.

- Desenvolvimento de alguns VANTs físicos: As figuras 6, 7, 8, 9 e 10 apresentam exemplos de alguns modelos. 


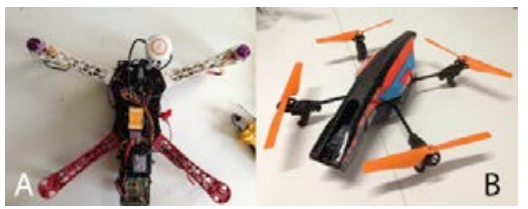

Figura 6 - Customização de multimotores DJI (A) e Parrot (B).

Fonte: Elaborado pelos autores.

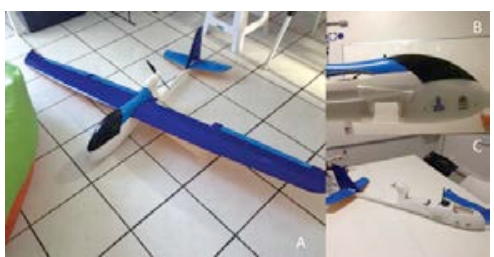

Figura 7 - Customização do avião Raptor(A) com controladora APM (C) e adaptação para câmera fotográfica (B).

Fonte: Elaborado pelos autores.

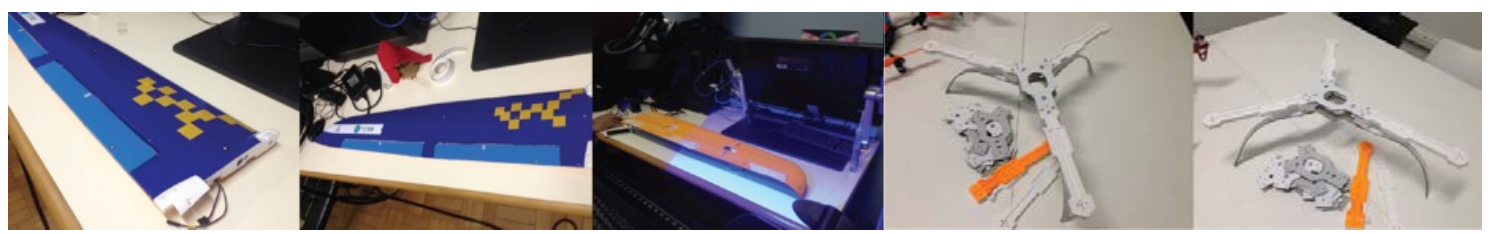

Figura 8 - Digitalização em scanner de inspeção 3D para customização e usinagem; e Projeto do NASDESIGN e fabricação por usinagem CNC de drone com tipologia de frame com 3 e 4 braços. Fonte: Elaborado pelos autores.

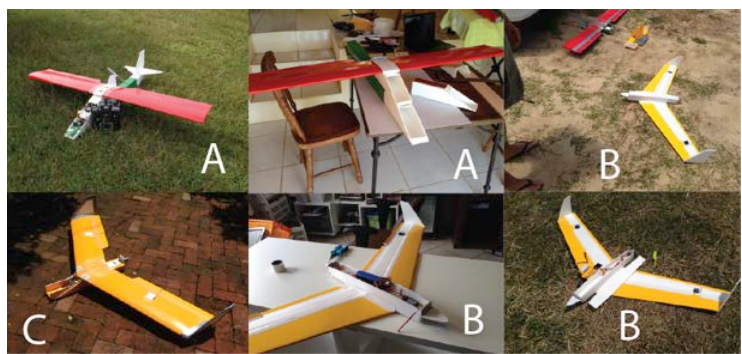

Figura 9 - Fabricação de baixo custo de avião (A), do tipo asa (B e C) open source. Fonte: Elaborado pelos autores.

\section{- Os VANTs em atividade: monitomento ambiental}

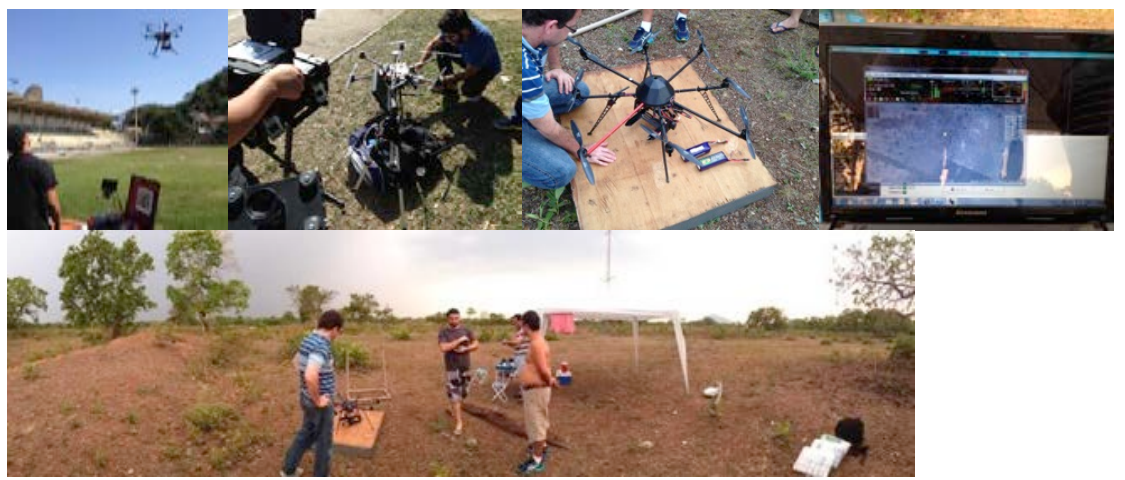

Figura 11 - Teste de vôo para calibração de câmera e vôo experimental. Fonte: Elaborado pelos autores.

- Modelagem virtual 3D de VANT: Pode ser utilizado qualquer software de modelagem parametrizado, nesse proposta se sugere a utilização do SolidWorks 
(ferramenta de CAD, Computer-aided design) que é uma computação paramétrica onde se cria objetos tridimensionais a partir de formas geométricas. A criação de sólidos ou superfícies começa com a definição de esboços 3D, esses esboços definem a conectividade e certos relacionamentos geométricos entre vértices, linhas e curvas. Um dos pontos fortes, além da parametrização aplicada aos objetos, é a capacidade de modelagens híbridas em que se aproveitam entidades sólidas e de superfícies para gerar modelos complexos. (BOCCHESE, 2009).

- Desenvolvimento de alguns VANTs virtuais 3D no solidworks: O SolidWorks é muito bom para o ensino do design, principalmente o de produto, por favorecer o ensino do desenho industrial. A figura 13 apresenta exemplos de Drones modelados em solidworks.

$\bullet$

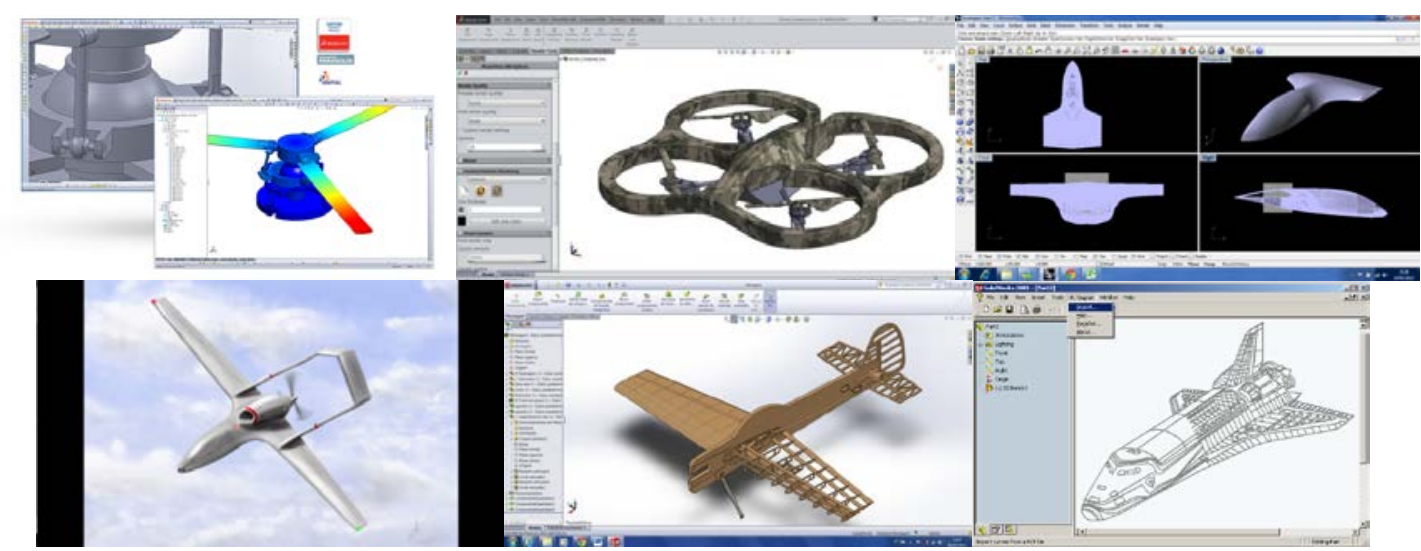

Figura 13 - Exemplos de Drones.

Fonte: Elaborado pelos autores.

\subsubsection{Prática 2: Modelagem de personagem minimalista}

A autora Eliete ministrou disciplinas para o curso de Design de produto quando trabalhou como professora substituta na UFSC - na qual foram elaboradas e executadas todas as etapas da modelagem de um personagem minimalista.

- Construção do modelo físico: Podem-se observar os materiais e todas as etapas do processo de construção do personagem (possui sólidos básicos) vide figura 14 .

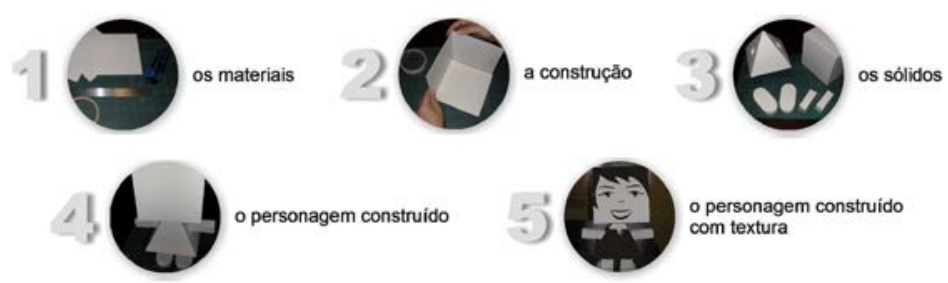

Figura 14 - Os materiais usados, o processo de construção e o personagem.

Fonte: Elaborado pelos autores.

- Construção do modelo virtual: Foi escolhido o software Blender para modelar o personagem, por ser gratuito e atender a proposta do trabalho, mas pode ser utilizado outro software. A seguir será apresentado todo o processo de construção do personagem digital. O Blender é um software de modelagem e animação 3D de código aberto, permite a criação de jogos sem programação e a realização de pósprodução de animações com um editor de vídeo integrado (MACHADO \& 
MORAES, 2005; BRITO, 2016). Também permite que qualquer objeto modelado seja exportado para o formato VRML (Virtual Reality Modeling Language, ou Linguagem para Modelagem de Realidade Virtual) ou OBJ. Arquivos nestes formatos descrevem vértices e arestas que podem ser importados para uso na OpenGL com uma simples leitura do arquivo (MACHADO \& MORAES, 2005). A Figura 15 mostra a modelagem virtual do personagem e suas vistas ortográficas.

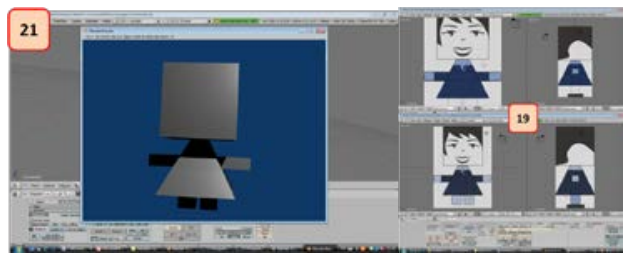

Figura 15 - Modelagem virtual do personagem e suas vistas ortográficas.

Fonte: Elaborado pelos autores.

\subsection{Etapa 3 - Fechamento}

Os trabalhos desenvolvidos serão disseminados através de artigos, pôsteres, panfletos/cartazes às comunidades, sites, blogs, apresentação de seminários, etc. organizado pela universidade e escolas. O grupo de cada escola apresentará a ela com apoio dos envolvidos representando a universidade. Após as apresentações os trabalhos serão na universidade e nas escolas.

\section{CONCLUSÃO}

Como resultados se esperam as trocas de conhecimento e responsabilidade conjunta, momentos em que são apresentados dados que mostram as necessidades da comunidade, aspirações para melhor interatividade profissional, características e a cultura da população abordada. E como benefício, a universidade, alunos e professores aprendem a reconhecer novos valores culturais e características das pessoas que constituem este meio social. Desde o início dos encontros procura-se estabelecer tranquilidade e harmonia em seu desenvolvimento buscando a motivação na interdisciplinaridade praticada, nas trocas de experiências profissionais, nos valores culturais adquiridos ao longo do tempo e na confiança entre os participantes.

Para se alcançar o objetivo deste projeto é fundamental que a metodologia seja flexível, coerente com a realidade local, com convicção e simplicidade por parte dos alunos e professores em relação ao seu procedimento, sempre norteados pelas trocas de experiências, de forma que as metas possam ser alcançadas de forma harmoniosa, saudável e consciente de suas responsabilidades. Não se devem esquecer as dificuldades que o grupo de extensão e os participantes irão apresentar, como: inexperiência dos alunos/professor com os trabalhadores. Pode-se citar os benefícios a conseguir para o ensino médio e para a Universidade, decorrentes das atividades a serem realizadas através da implementação deste projeto de extensão, são eles:

- Para a Comunidade Externa (escolas de ensino médio, ensino profissionalizante, empresas): Alunos e profissionais motivados pela novidade da situação de aprendizagem; Professores com uma visão mais ampla de opções profissionais para recomendar aos seus alunos; Professores com material didático novo para usarem em suas aulas; Professores sabedores da possibilidade de cooperação com seus colegas universitários. 
- Para a Universidade: Alunos de graduação com atividade extracurricular enriquecedora de sua formação; Prática da exposição oral e laboratorial dos trabalhos dos alunos de graduação e de pós-graduação; Alunos de graduação e de pósgraduação motivados para a docência; Secretários e técnicos de laboratório, etc, motivados por exercer tarefa fora da rotina de trabalho. Integração e cooperação entre os membros da comunidade; Geração de multiplicadores (alunos e professores participantes) nas escolas de ensino médio, divulgando uma imagem positiva da Universidade; Professores da universidade.

\section{REFERÊNCIAS}

BANDEIRA, D. A.; MATOS, A. C. X .; AGUIAR, M. P.; MIZUKAVA, N. Y.; LARA FILLHO, S. A. Arte e Tecnologia Aspectos do conceito e da criação e a modelagem 3D em RPG educativo para computadores. 2008. Disponível em: <www.arte.unb.br/6art/textos /andressa.pdf >. Acesso em: 20 dez. 2015.

BASTOS, F. P.; FIM, A. T.; MAZZARDO, M. D. Ambientes virtuais de ensinoaprendizagem: os desafios dos novos espaços de ensinar e aprender e suas implicações no contexto escolar. Novas Tecnologias na Educação/CINTED-UFRGS. V. 3 № 1, Maio, 2005.

BIEMBENGUT, Maria Salett; HEIN, Nelson. Modelagem matemática no ensino. São Paulo: Contexto, 2000, 127p.

BOCCHESE, C. Solidworks, projeto e desenvolvimento. São Paulo: Erica, 2009. 288p.

BRITO, A. 2016. Disponível em: <https://ead.allanbrito.com/>. Acesso em: 20 jan. 2016.

LAKATOS, E.M.; MARCONI, M.A. Metodologia Cientifica. 6. ed. São Paulo: Atlas, 2011. MACHADO, L. S., MORAES, R. M. 2005. Cenários 3D Interativos com Software Livre. RITA, Volume XII, p. 91-112.

SANTOS, E. D.; MELHADO, S.; MONICE, S.; GRILO, L. Possibilidades de aplicação e limitações da realidade virtual na arquitetura e na construção civil. 2008. Disponível em: <http://toledo.pcc.usp.br/pdf/realidade_virtual.pdf>. Acesso em: 10 dez. 2015.

SCHEFFER N.; DALLAZEN A. B. O uso de software livre e a modelagem matemática. 2008. Disponível em: <http://ccet.ucs.br/eventos/outros/egem/minicursos/ mc27.pdf>. Acesso em: 10 dez. 2015.

SCHEFFER, N. F. Modelagem Matemática: Uma abordagem para o EnsinoAprendizagem da Matemática. In: EDUCAÇÃO MATEMÁTICA EM REVISTA - RS n.1, 1999. p.11-16.

SPECK, H. J. Proposta de método para facilitar a mudança das técnicas de projetos: da prancheta à modelagem sólida (cad) para empresas de engenharia de pequeno e médio porte. Florianópolis - Brasil, 2005. Tese de doutorado. Programa de PósGraduação em Engenharia de Produção Universidade Federal de Santa Catarina.

THIOLLENT, Michel; ARAÚJO FILHO, Targino de; SOARES, Rosa Leonôra S. (coord.) Metodologia e experiências em projetos de extensão. Niterói-RJ: EDUFF, 2000. 